\title{
Pensar la bioética desde la "multiversidad" latinoamericana
}

Dr. Luis Justo,

Universidad Nacional del Comahue y Programa de Enseñanza en Bioética de la UNESCO, Argentina.

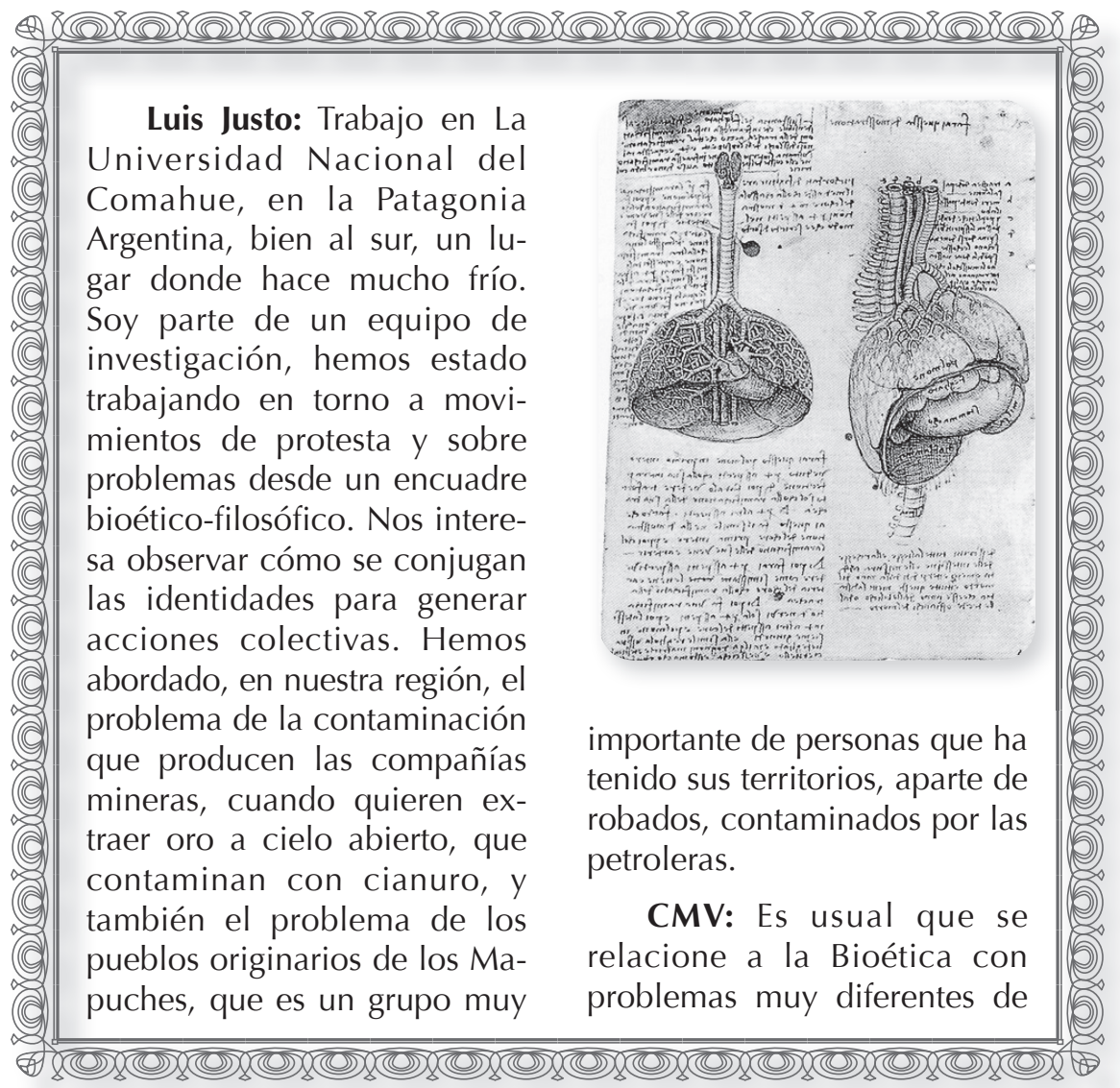


los que usted ha mencionado. Agreguemos que el énfasis que pone en la diversidad cultural o étnica, así como el tema de las identidades, es, para muchos bioeticistas, contrario a una noción de universalidad ligada a los famosos principios de la Bioética, el Ilamado "Consenso de Georgetown". ¿Qué piensa usted sobre esto?

LJ: Yo pienso que toda acción en salud es una acción política. Es imposible desconectar lo que le pasa a un ser humano - desde el punto de vista de su salud- de las circunstancias políticas y económicas en las cuales vive. Esto no es ningún invento, ya lo decía Virchow, en el siglo XIX, cuando describió las condiciones de los mineros en Silesia. Lo que él planteó, justamente, fue que la forma adecuada para solucionar los problemas de salud de los mineros y otras personas en Alemania era cambiar la sociedad, y que, si las condiciones de la sociedad no cambiaban, eran inútiles las acciones que se pudieran tomar, ya que al final se transformaban únicamente en acciones paliativas. Y él planteó que, en cierta manera, la política y la medicina eran la misma cosa. Además, fue un gran anatomopatólogo que todavía se sigue estudiando en las escuelas.

Por su parte, Engels, en su descripción de la clase obrera en Inglaterra, también hace un análisis desde el punto de vista de la salud pública. Así que tenemos antecedentes. Y en este sentido hay dos formas de mirar: ver hacia la clausura, terminar cerrando los problemas del apéndice en el apéndice y los problemas del corazón en las coronarias, o mirar hacia la apertura y tratar de ver qué es lo que nos pasa como seres humanos en medio de esta situación social, en la cual uno pensaría que es casi imposible estar sano.

Entonces, aunque uno piense que dadas las situaciones de nuestras sociedades es casi imposible estar sano, debería ir avanzando en una línea de pensamiento que le permita pensar o hipotetizar que la forma de estar sano es rebelarse, y que la forma de rebelarse es la acción política.

Hay un catalán que se Ilama Jordi Gol que dice que la salud es el estado en el cual podemos llevar adelante una vida autónoma, solidaria y gozosa. Me gusta esta definición que plantea que uno puede estar enfermo de forma sana, pero también puede estar sano de maneras enfermas. Si uno está sano en medio de esta catástrofe universal que estamos viviendo, uno puede preguntarse si eso no es una salud enferma, de alguna manera. $\mathrm{Y}$ bien, dentro de ese ámbito es que está en juego y en revisión la concepción de la Bioética, así como la misma concepción de la ética. Hay un autor que me atrae mucho, Enrique Dussel, quien trabaja en ética de la liberación, y otro grupo grande de gente que trabaja en la ética de la liberación.

Ahora, sobre lo del universalismo ético, yo no diría que haya que rechazarlo ni afirmar el particularis- 
mo; más bien, diría que debemos comenzar a trabajar desde miradas, como dice Mignolo, con un pensamiento "descolonial". Es empezar a corrernos de la mirada eurocéntrica y ver qué es lo que podemos generar con un pensamiento independiente que vaya recogiendo las voces que históricamente en Latinoamérica han estado suprimidas, que han estado marginadas y a las que no se les ha permitido participar.

La Bioética es un invento estadounidense, lo cual no está mal. No diría que todas las cosas que han inventado los estadounidenses son malas —de hecho, han inventado el "velcro", un "gran avance" de la cultura-, pero el caso es que ellos empezaron a trabajar, luego de la Segunda Guerra Mundial, en torno a los problemas de Bioética, y determinaron en Europa el Código de Nuremberg, que condenaba los experimentos que habían hecho con los prisioneros judíos en los campos de concentración, lo cual no impidió que sus fuerzas armadas, en los Estados Unidos y con los estadounidenses, aplicaran las mismas cosas que habían hecho los nazis en los campos de concentración, no en la misma escala, por cierto. Pero sí que hicieron una serie de experimentos, por ejemplo, sobre los efectos de la radiación - ya que se desarrollaron durante la Guerra Fría-y, sin pedir el consentimiento de las personas, se les sometía a la radiación o se les inyectaba sustancias peligrosas. En fin, se trata de barbaridades que ocurren incluso dentro de los mismos "países desarrollados".
Dos estadounidenses, Beauchamp y Childress, escribieron un famoso libro de principios de la ética biomédica en el que, de alguna forma, hicieron lo que los argentinos llamamos "marcar la cancha", de tal suerte que después todo el mundo ha tenido que discutir lo que ellos dijeron, porque fueron los que marcaron el terreno de la discusión. Y comenzaron a trabajar a partir del principialismo, con la siguiente cosa curiosa: ellos aclaran que parten de lo que Ilaman "la moral común basada en principios", referida a su pueblo, a su país, a sus situaciones. Incluso los ejemplos que ponen en su texto son ejemplos vinculados a su realidad, por ejemplo, qué acciones voy a comprar en el mercado accionario y otras por el estilo.

CMV: Que es también la realidad de los estadounidenses de clase media para arriba...

LJ: Precisamente, ese es el grupo que ellos toman como grupo de referencia para formular sus principios, los cuales son bastante buenos —no es que sean malos en sí mismos, ni cosa por el estilo. Pero, después, por alguna razón que uno no termina de entender del todo bien, se universaliza lo que ellos dicen que está referido a la moral común de un pueblo; lo que sitúan históricamente, basados en los principios de un grupo específico, se toma como universal. Yo no creo que ellos sean imperialistas. Son personas que han ido revisando la 
edición de su texto muchas veces. De hecho, uno es deontologista y el otro es utilitarista, y es evidente que tienen una posición realmente abierta, algo que nos convendría tener a todos. Ellos no se cierran sobre sí mismos, no dicen "esta es la verdad". Pero parece que la dinámica histórica provoca que, cuando recibimos estas cosas, las recibamos "como si fueran la verdad", así como los mandatos de consumo son recibidos y nos volvemos consumistas, o como recibimos el cristianismo y lo reproducimos en formas apropiadas y en formas no apropiadas, en contextos en los cuales puede ser más o menos aplicable y en contextos en los cuales no lo es para nada.

Por ejemplo, donde yo trabajo, en la parte más al sur de la cordillera de Los Andes, hay muchas comunidades de pueblos originarios y además hay muchas comunidades rurales andinas, pequeñas comunidades que tienen dinámicas sociales totalmente distintas a las dinámicas urbanas y esto es un tema que aún no hemos trabajado. Hay un solo grupo que trabaja en el tema de Bioética rural —en el estado de Montana, en Estados Unidos-, donde los códigos son totalmente distintos. Por ejemplo, lo que significa privacidad y confidencialidad en el ámbito rural hay que revisarlo, deteniéndonos un poco y poniéndonos a repensar las cosas. Yo admiro mucho los trabajos de Volnei Garrafa $y$, en general, los que realizan los investigadores brasileños, ya que van adelante en el tema de la Bioética, y además tienen un espíritu de país.

CMV: Esta nueva manera de ver las cosas, ¿afecta también a nuestras ideas sobre los derechos humanos?

LJ: Los latinoamericanos pensamos si no sería mejor repensar el punto de partida de la Bioética, que hasta ahora ha sido el principialismo, y, sin descartarlo, pensar una Bioética fundamentada en los derechos humanos. Estos no pasan por un eje de sociedad de estructura en base al mercado, sino que pasan por un eje de sociedad de estructura en base a los derechos que corresponden a todos los seres humanos. Esto es bueno y como propuesta es interesante. Yo creo que tenemos que trabajar más y adherirnos mucho a esto. Pero la concepción misma de derechos humanos es una concepción propia de la Ilustración y se origina en una situación que es colonial: al país que se le propone esto, "lo van llevando adelante" otros países que son originalmente colonizadores. Esto no quiere decir que nosotros no podamos tomar los derechos humanos y desarrollarlos en otros sentidos múltiples, pero el asunto es no desarrollarlos en forma colonial, no imponerlos a sangre y fuego en medio de cosmovisiones diferentes. En este sentido, es que viene el enganche con lo que Boaventura de Sousa Santos Ilama una "hermenéutica diatópica"; es decir, trabajar desde topoi distintos, admitiendo que el de cada uno es incompleto. O sea, que ninguno de nuestros sistemas resuelve totalmente todas las preguntas posibles, 
y siempre nos quedan huecos y cosas que no podemos terminar de complementar, y que, por lo tanto, si son incompletos, podemos tener espacios de diálogo e intercambio.

También están esas otras ideas que proponen Mignolo, Quijano y otros: esta especie de "pensamiento híbrido", pensamientos mestizos desde la situación colonial, pero con la intención de "escapar" de esa situación colonial. Citan a un autor que se Ilama Guamán Poma, quien es un indio peruano nacido en el siglo XVI, que le escribe al rey de España en lo que él llama "nueva crónica", una crónica hecha desde su punto de vista. Es realmente muy interesante. Ellos lo propondrían como primer ejemplo de pensamiento híbrido, ya que, con mucha habilidad, toma todo el argumento de la religión católica para decirles a los españoles: "Ustedes, señores, no son cristianos ni son católicos". Es una crítica fuerte utilizando sus propios argumentos y plantea una especie de alianza con el rey, según la cual el rey de España y los incas se encontrarían al mismo nivel. Es una mirada absolutamente distinta. Este documento quedó archivado en una biblioteca danesa y lo rescataron en 1908.

Guamán Poma parece ser un precursor de este "enfoque", de esta obligación de asumir que estamos enquistados dentro de una mirada prefijada. Eso es lo que creo que tendríamos que empezar a hacer nosotros. Nuestras estructuras de gobierno, nuestras estructuras de educación, en Latinoamérica, han sido estructuras creadas por la elite colonizadora. Los colonizadores, con cierta sensatez, decidieron aliarse con grupos del lugar y darles poder, lo mismo que han hecho en África y en Asia, generando así estructuras educativas, jurídicas, etc. Las universidades latinoamericanas están enganchadas todavía en ese proyecto, no estamos desmarcándonos de eso. Si uno se fija en lo que es la estructura de poder en las universidades latinoamericanas - debe haber excepciones que yo no conozco, puede que las haya-, la mayor parte son estructuras de poder vinculadas a un pensamiento cientificista, etc. No está mal ser científico, así como tampoco está mal ser "liberal", pero el caso es que dichas estructuras están orientadas más bien hacia posiciones muy conservadoras. Parece ser que en Perú o en Ecuador hay una "multiversidad" que está intentando otros caminos.

CMV: ¿En el terreno de las universidades?

LJ: Sí, creo que sí.

CMV: ¿Estos otros caminos suponen un replanteamiento de los presupuestos epistemológicos?

LJ: Yo creo que sí, pero es una tarea inmensa. Si uno lo dice, parece que fuera sencillo. Creo que los que queremos trabajar la Bioética en América Latina tenemos precisamente una "deuda de pensamiento" sobre este asunto.

CMV: Y aquí podríamos volver a la conexión entre Bioética y derechos humanos... 
LJ: Esa es una de las cosas que tenemos actualmente en elaboración. La Bioética principialista tiene sus ventajas; además, lleva inserto uno de los núcleos fundamentales del pensamiento occidental: el binomio formado por la propiedad y la autonomía. Pero, como dice un autor que trabaja en sociología de la salud, Paul Wall, ¿por qué la autonomía ha tenido tanto éxito en el ámbito de la Bioética y de la salud estadounidense? Habría que decir, en primer lugar, que la autonomía plantea casi una obligación perfecta: no hay que interferir con las posibilidades de elección de la persona. Se trabaja sobre la idea de las libertades negativas, más que sobre la idea del derecho a la salud, que es una tarea absolutamente imperfecta y positiva. Si nos limitamos a plantear la no interferencia, en el sentido tradicional, podemos formular códigos con mucha más facilidad. Es mucho más fácil decir "no debo dañar a alguien" que decir "debo ayudar a alguien".

CMV: En su conferencia, usted relacionaba esta posición con las ideas de la filósofa Onora O’Neill...

LJ: En efecto, ella plantea seriamente que no puede existir algo así como el derecho a la salud...

CMV: ...Pues se trataría de un derecho positivo...

LJ: ....No solo porque sería un derecho positivo, sino porque sería una obligación absolutamente imperfecta, que es muy difícil llevar adelante. Por lo tanto, no hay al- guien a quien yo pueda hacer responsable de resolver estos problemas y tampoco se sabe exactamente cuáles son. Amartya Sen refuta esto, ya que dice que el hecho de que no haya un responsable directo no quiere decir que no se puede formular un derecho; y que en sí los derechos humanos nos generan obligaciones que son muchas veces imperfectas. Por ejemplo, la obligación de agitación en favor de que se cumplan. $Y$, entonces, dice que esta dificultad de formulación no implica que un derecho no pueda ser considerado dentro del grupo de los derechos humanos.

Hay un autor, que es realmente importante en el campo de la filosofía política, Robert Nozick, cuya escuela de pensamiento - así como muchas otras similares - plantea que es impensable la idea de que pueda existir algo así como el derecho a la salud, ya que la forma adecuada de distribuir los bienes es a través del intercambio, mediado o no por dinero, y acá se nos complica la cosa porque agregan la herencia, y entonces se le complica la cuestión a él mismo, pues se da cuenta de que hay un momento en que esto no termina de cerrar...

CMV: ....Nozick es un libertario extremo...

LJ: ...Claro, pero él dice que no es legítimo adquirir los bienes por la fuerza. Si yo voy y le saco a alguien su terrenito pegándole con un palo en la cabeza está mal. Lo que es legítimo es el intercambio sin coerción de ningún tipo, pero, 
cuando admite la herencia, admite la posibilidad de que intercambios ilegítimos se transmitan a través de las generaciones, con lo que tendríamos que plantear un principio "rectificatorio" (él, con la lucidez que le caracteriza, se da cuenta de esto). Pero después termina aclarando que esto significa retroceder hasta Adán y Eva, y esto es imposible. Por lo tanto, sostiene, tomemos la situación "como está ahora" y esto congelaría las relaciones de propiedad según como están planteadas "en este momento", lo cual, evidentemente, deja mucho que desear. En todo caso el planteamiento rawlsiano es mucho más satisfactorio desde el punto de vista del liberalismo igualitarista...

CMV: Yo creo que incluso algunos utilitaristas son más satisfactorios que Nozick. Por ejemplo, Sen, que es un consecuencialista. En cierto modo, también es mejor Martha Nussbaum. Ambos toman en cuenta ciertos factores intuitivos, así como la moral del día a día. Y es que suena chocante escuchar que no existe un derecho a la salud. Esto es algo que choca incluso con valores presentes en culturas donde los valores liberales son predominantes. También a un estadounidense medio podría sonarle muy extraño, aún cuando se pongan sobre la mesa los conflictos con el derecho a la propiedad, a la libre elección, etc., prima facie, las personas piensan que tienen derecho a la salud, no es algo que creen que se puede tener $y$ luego ya no...
LJ: ...Pero viven dentro de un sistema en el cual no tienen ese derecho. Si uno se fija en cuál es el principio rector del sistema de salud estadounidense, no es el derecho a la salud; al contrario, se parece más a lo que propone Nozick, en el sentido de que obtiene la salud quien la puede adquirir en el mercado. Ahora bien, ellos se dan cuenta de que es un planteamiento absolutamente "antipático" y desagradable, por lo que le agregan lo que llaman el "mínimo decente" (decent minimum). O sea que la salud es un bien como cualquier otro, que debe comprarse y venderse en el mercado de la salud —el acceso a la atención, para hacerlo más preciso-; pero por razones de humanidad no podemos dejar que los muertos de hambre no tengan ningún acceso a la salud. Entonces, por caridad, no por derecho - la caridad no es exigible-, sería bueno que dedicáramos fondos para darles un mínimo decente. Esto significa que habría un mínimo decente para los que no tienen nada $-y$ cuán decente es ese mínimo es algo absolutamente debatible-, pero fundamentado sobre la caridad, no sobre el derecho, que sí es exigible. $Y$ el resto del sistema estadounidense es un sistema de compra-venta para el que lo puede pagar, lo que implica que la gente se desespera, adquiere hipotecas para poder pagar, se llega a la quiebra económica... La quiebra familiar por gastos médicos en Estados Unidos, en los últimos diez años, es una cosa verdaderamente terrible. 
Ahora bien, parece ser que para los estadounidenses la construcción de Nozick es la viable, porque teniendo la oportunidad de votar por un presidente que proponía un sistema de salud un poco más solidario, votaron por el que no lo proponía, ya que esto habría supuesto más impuestos, y en la concepción de Nozick los impuestos son confiscatorios, son un robo del legítimo trabajo de una persona. Por supuesto, así no se deja abierta ninguna instancia para la solidaridad, ni siquiera liberal. Al contrario, el planteamiento "liberal igualitarista fuerte" de los países escandinavos, por ejemplo, supone una tasa impositiva elevada...

CMV: Tiene un carácter más rawlsiano...

LJ: Claro, Rawls admite esto abiertamente cuando señala que podemos hacer diferencias favoreciendo a los que están en peor situación. A eso se debe el enfrentamiento entre Rawls y Nozick, algo por otra parte admirable, ya que tanto Rawls como Nozick estaban en la misma universidad y se intercambiaban sus textos antes de publicarlos para que el otro los criticara, sabiendo que estaban en las antípodas en cuanto a su pensamiento. Y hacían esto con respeto, no como es usual entre nosotros, que nos apasionamos, nos peleamos y denigramos al que piensa diferente. Además que esta actitud les permitía fortalecer sus argumentos.

CMV: Pienso en dos cuestiones: Por un lado, los críticos de posturas como la de Nozick apelan al sentido de humanidad de las personas, a una especie de "sentido común moral". Pero, además, filosóficamente se argumenta que los planteamientos deben articularse con un mínimo de consistencia. Por ejemplo, Rawls hace un gran esfuerzo para que sus principios encajen; en cambio, eso de meter la caridad, como si fuese una especie de "pegoste", es teóricamente problemático. Es preferible una buena articulación de la cadena de razonamientos que sostienen una propuesta ética que tener que recurrir a principios ad hoc...

LJ: Hay un argentino, Atilio Borón, que le hace una crítica interesante a Rawls, aplicable a todo el pensamiento liberal igualitarista, y consiste en señalar que todos ellos aceptan la propiedad privada de los medios de producción...

CMV: Claro, Borón es marxista...

LJ: ...Sí, y con esa crítica se hace un desplazamiento radical, pues en la medida en que se reconoce la validez de ese señalamiento, todo se modifica. Y bien, de todas maneras, creo que en el ámbito de la Bioética el marxismo no tiene aún ninguna voz que lo represente.

CMV: Es una lástima.

LJ: Sí, es una lastima. Y es una tarea que habría que hacer. Yo soy incapaz de hacerlo porque me falta formación, pero si alguien pudiera hacerlo sería extremadamente valioso. No me quiero meter en los 
debates de si el marxismo tiene o no posturas contra alguna moral, etc. No me quiero meter en ese terreno, pues soy médico y no filósofo. En nuestro equipo de investigación hay varias filósofas; a mí me interesa buscar las herramientas que me sirven como médico. ¿Que para qué me sirven? Pues para intentar cambiar la realidad. Si pensara que la Bioética no sirve para cambiar la realidad, no me interesaría.

CMV: En conexión con esto último, ¿cómo entiende a la "medicina basada en la evidencia" y sus implicaciones éticas? ¿Cuál es la base sobre la que deberíamos entenderla?

LJ: La medicina basada en la evidencia, por lo que yo pesco y que es bastante poco - no me dedico a eso ni soy un estudioso, como los que han venido acá-, surge como un criterio antiautoritario y antiverticalista, en un oficio - por que yo no creo que sea una ciencia la medicina- que se viene manejando con criterios de autoridad durante muchísimo tiempo, y en el cual, tradicionalmente, las personas pensantes han tenido dificultades, las personas que, como diría María Noel [Lapoujade], hacen uso de la imaginación.

Un ejemplo lo tenemos en Semmelveis, un médico vienés del siglo XIX, quien observaba que las mujeres parturientas que eran atendidas por los estudiantes se morían en gran cantidad, mientras que las que no eran atendidas por los estudiantes ni mayormente por nadie terminaban pariendo solas y eran muchas menos las que se morían. Y él se puso a pensar y terminó postulando algo así como la teoría microbiana, diciendo que lo que había que hacer era lavarse las manos. Él no conocía los microbios, no había microscopio, la teoría microbiana no estaba formulada todavía, y tal fue el rechazo de la Academia que terminó por morirse - no recuerdo si se suicidó o si murió en la miseria, aunque en todo caso se trató de una tragedia. Pero lo que hizo en realidad fue observar la evidencia y a través de esa evidencia formular una hipótesis que después se probó como correcta: si se hacía lo que él decía, se morían muchísimo menos mujeres en el parto. Pero el criterio de autoridad impedía que la evidencia se aceptara y se aplicara como tal.

Después, la metodología de los ensayos clínicos ha ido mejorando con el tiempo, y se llegó a la formulación del ensayo clínico doble ciego o placebo controlado, que es una forma más de trabajar en investigación. No es la única, hay formas más adecuadas para otros problemas, o sea, sirve para unos problemas y no para otros.

CMV: De hecho, el recurso al placebo es algo muy cuestionable en una gran variedad de situaciones...

LJ: ...Exactamente. Pero, bien, en ese sentido, lo que se ha llamado medicina basada en la evidencia busca categorizar estas formas de producir nuevo conocimiento, 
señalando que hay formas más confiables y otras menos confiables. Básicamente es eso. Y, en el fondo, lo que nadie quiere decir con franqueza es que los médicos tienen que estudiar todos los días y no pueden decir que no tienen tiempo para estudiar porque están muy ocupados, ya que estudiar debería ser precisamente una parte de ese "estar ocupados".

En general, los médicos no estudiamos. A los médicos nos actualizan los visitadores de los laboratorios farmacéuticos o alguna que otra revista, pero estudiar seriamente, dedicarle un par de horas diarias al estudio, eso no lo hacemos. Y esto es así porque nos hemos insertado en el sistema taylorizado de producción, en el que tenemos que producir muchas unidades de atención, y además eso nos rinde más económicamente. En cambio, las dos horas de estudio no nos rendirían nada económicamente.
Ahora bien, en nuestra escuela de medicina aplicábamos una estructura un poco diferente: trabajábamos sobre la idea de que lo que teníamos que enseñar, sobre todo, era a hacerse preguntas y a buscar la respuesta, no a memorizar respuestas; ya que dentro de diez años no iban a ser muy útiles, sino a reflexionar clínicamente frente a una persona necesitada. Esa fue una de las tareas lindas que tuve, como tutor de los talleres de los chicos, pues les presentábamos un caso y tenían tres semanas para buscar material, hacer hipótesis, contrastar las hipótesis con lo que se sabía y resolverlo de alguna forma. Mi objetivo era que aprendieran a hacerse preguntas, que aprendieran a buscar por su cuenta las respuestas. No sé cómo nos habrá ido, porque hay que ver qué es lo que ha pasado después de diez años, pero esos eran nuestros objetivos. 